\title{
Trait Anxiety as a Mediator of the Association between Attention Deficit Hyperactivity Disorder Symptom Severity and Functional Impairment
}

\author{
Yunhye $\mathrm{Oh}^{1,2}$, Hee Joon Yoon ${ }^{1}$, Ji-Hae Kim ${ }^{1}$, Yoo Sook Joung ${ }^{1}$ \\ ${ }^{1}$ Department of Psychiatry, Samsung Medical Center, Sungkyunkwan University School of Medicine, ${ }^{2}$ Department of Psychiatry, National Center \\ for Mental Health, Seoul, Korea
}

\begin{abstract}
Objective: Anxiety has been shown to influence functional impairment in patients with attention deficit hyperactivity disorder (ADHD). This study aimed to compare functional impairment in subjects with and without adult ADHD and to investigate the associations among trait anxiety, functional impairment, and ADHD symptom severity. Moreover, the effects of ADHD symptom subtypes on trait anxiety and functional impairment were also examined.

Methods: The sample included 209 adults between the ages of 20 and 31 years. Fifty-one adults received a diagnosis of ADHD, and an additional age, sex-matched group of 51 adults comprised the adult control. Participants were assessed with Conners' Adult ADHD Rating Scales (CAARS), the Beck Depression Inventory (BDI), the Spielberg Trait Anxiety Inventory (STAI-T), and the Sheehan Disability Scale (SDS). The relationships among ADHD severity, anxiety, and functional impairment were investigated using Pearson's correlation analysis. Subtypes of ADHD symptoms that predicted anxiety and functional impairment were investigated using regression analyses.

Results: Adult ADHD patients significantly differed from normal control subjects according to BDI, STAI-T, and SDS assessment. Significant positive correlations were noted between ADHD severity, anxiety, and functional impairment. Multiple linear regression analysis confirmed anxiety as a mediator between functional impairment and ADHD CAARS symptom subscales.

Conclusion: Patients with adult ADHD showed higher levels of anxiety, depression, and functional impairment. Additionally, ADHD symptoms and anxiety impacted subject functional impairment. Our results suggest that anxiety may be a strong mediator between ADHD severity and functional impairment.
\end{abstract}

KEY WORDS: Attention deficit-hyperactivity disorder; Comorbidity; Quality of life; Anxiety.

\section{INTRODUCTION}

Attention deficit hyperactivity disorder (ADHD) is a neurodevelopmental disorder characterized by inattention, hyperactivity, and impulsivity. ${ }^{1)}$ ADHD develops during preschool. While hyperactivity tends to decline with age, symptoms of inattention are more likely to persist to adulthood. ${ }^{2,3)}$ The rate of ADHD persistence to adulthood is $65 \%$, including a partial remission state.

Received: May 4, 2017 / Revised: July 22, 2017

Accepted: August 26, 2017

Address for correspondence: Yoo Sook Joung, MD, PhD

Department of Psychiatry, Samsung Medical Center,

Sungkyunkwan University School of Medicine, 81 Irwon-ro,

Gangnam-gu, Seoul 06351, Korea

Tel: +82-2-3410-3589, Fax: +82-2-3410-0050

E-mail: yschoung@skku.edu

ORCID: https://orcid.org/0000-0002-9225-4643
Adult ADHD is prevalent (demonstrated in approximately $4.4 \%$ of adult populations), ${ }^{4,5)}$ and causes substantial functional impairment. ${ }^{6,7)}$ Adult ADHD is associated with psychiatric disorders such as mood disorder, anxiety disorder, or substance abuse, as well as antisocial and illegal behaviors. ${ }^{8,9)}$ Accordingly, adult ADHD causes long-term health and economic burdens, including medical health, education, social service, and criminal justice costs. ${ }^{10-12)}$ Despite the consequences of the clinical implications of adult ADHD, little clinical attention is paid to adult ADHD. ${ }^{13)}$ In fact, fewer than $20 \%$ of adults with ADHD are diagnosed or treated, and the majority of adult ADHD patients remain untreated or in states of partial remission. ${ }^{14-16)}$ If adult ADHD were to be successfully diagnosed and treated, then the progression of these individuals to further functional impairment could be pre-

(c) This is an Open-Access article distributed under the terms of the Creative Commons Attribution Non-Commercial License (http://creativecommons.org/licenses/by-nc/4.0) which permits unrestricted non-commercial use, distribution, and reproduction in any medium, provided the original work is properly cited. 
vented. $^{17)}$

Recent studies have demonstrated significantly higher functional impairment in adults with ADHD compared to normal controls. ${ }^{18)} \mathrm{A}$ previous study also reported that the severity of ADHD symptoms was significantly correlated with impairment to patient quality of life. ${ }^{19)}$ These findings, however, are based on the results of studies conducted in Western populations. Little is known about the relationship between functional impairment and the severity of $\mathrm{ADHD}$ symptoms in Asian populations.

Anxiety is a commonly reported condition with a prevalence ranging from $34 \%$ to $40 \%$ in patients with ADHD. ${ }^{20,21)}$ Anxiety is a strong risk factor for other forms of psychiatric disorders, such as depression, somatoform disorder, conduct disorder, and substance abuse. ${ }^{22-25)}$ Anxiety adversely impacts self-esteem, social relationships, and academic performance. ${ }^{26-28)}$ In addition, anxiety is strongly associated with substantial functional impairment. ${ }^{29)}$ It is unclear, however, whether anxiety or the severity of ADHD symptoms are associated with functional impairment or whether anxiety mediates this relationship. Rigorous efforts to identify factors that relate functional impairment and ADHD are necessary in Asian populations in order to develop more therapeutically useful assessments and strategies for intervention.

The purpose of this study was to compare the severity of functional impairment in adults with and without ADHD, and to explore the mediating role of anxiety between ADHD symptoms and functional impairment.

\section{METHODS}

\section{Study Design}

The original sample consisted of 51 ADHD subjects and 158 normal control subjects. Patients with ADHD between the ages of 18 and 45 years were recruited from a set of psychiatric outpatients visiting Department of Psychiatry, Samsung Medical Center. For each ADHD subject, psychiatric assessment was conducted by master's level clinical psychologist using the Mini-International Neuropsychiatric Interview (MINI) ${ }^{30)}$ to confirm the diagnosis of ADHD and to identify comorbidities. Control participants were recruited via advertisements in Universities of Gyeonggi District and Seoul Metropolitan area in Korea. No clinical history was collected for the control group. Among the 158 healthy subjects in the control group, 51 participants were age, sex-matched to the ADHD group using propensity score matching. For most analyses, this group was designated the "healthy control" group. Thus the sample included 51 adult ADHD patients and 51 sex-matched healthy controls. Each subject was asked to complete psychological self-reports. ADHD severity was assessed with the Conners Adult ADHD Rating Scales (CAARS). ${ }^{31)}$ The CAARS consists of four subscales: inattention/memory problems, hyperactivity/restlessness, impulsivity/emotional lability, and problems with self-concept. The Beck Depression Inventory $(\mathrm{BDI})^{32)}$ and the Spielberg Trait Anxiety Inventory (STAI-T) ${ }^{33)}$ were also administered to assess depression and anxiety. Additionally, the Sheehan Disability Scales (SDS), ${ }^{34)}$ which has been widely used among patients with various psychiatric illnesses, was used to examine participant functional impairment and quality of life. The Institutional Review Board of Samsung Medical Center approved this study, and all participants provided written informed consent.

\section{Measurement}

\section{The Conners Adult ADHD Rating Scale (CAARS) ${ }^{31)}$}

The CAARS is a quantitative measurement tool used to assess adult ADHD symptoms. The scale consists of four subscales that measure inattention/executive function, hyperactivity/restlessness, impulsivity/emotional lability, and problems with self-concept. Each item is scored on a four-point Likert scale ranging from 0 to $3(0$, not at all or never; 1 , just a little or once in a while; 2 , pretty much or often; and 3, very much or very frequently). We used the Korean version (CAARS-K), ${ }^{35)}$ which has good internal consistency (Cronbach's $\alpha=0.79-0.85$ ).

\section{Beck Depression Inventory (BDI) ${ }^{32,36)}$}

The BDI is a well-validated scale designed to measure depressive symptom severity. It is a self-report questionnaire comprised of 21 items using a four-point Likert scale. Overall score varies between 0 and 63 , with score ranges of 0-13 (not at all), 14-19 (mildly), 20-28 (moderately), and 29-63 (severe). The Korean version of $\mathrm{BDI}^{36)}$ with good internal consistency (Cronbach's $\alpha=0.83-0.88$ ) and validity was used.

Spielberg Trait Anxiety Inventory (STAI-T) 33,37) $^{3}$

The STAI-T questionnaire is widely used to measure 
trait anxiety. The STAI-T contains 20 four-point Likert scale items. Trait anxiety items assess how subjects generally feel. Total scores range from 20 to 80 . Higher scores indicate more severe anxiety levels. The Korean version ${ }^{37)}$ used in this study had good reliability and validity.

\section{Sheehan Disability Scale (SDS) ${ }^{38,39)}$}

The SDS self-report questionnaire measures disability or functional impairment. It consists of three dimensions including work/school, social life/leisure activities, and family life/home responsibilities. Each item ranges from 0 to 10: 0 (not at all), 1-3 (mildly), 4-6 (moderately), 7-0 (markedly), and 10 (extremely). The total score ranges from 0 to 30 and higher scores indicate higher disability level.

\section{Statistical Analysis}

We assessed differences between ADHD and control subjects using $t$ tests for continuous variables and chisquare tests for categorical outcomes. Pearson correlation coefficients were used to evaluate relationships between clinical variables.

Mediation models were developed to examine the influence of ADHD symptom severity on functional impairment. Separate model were estimated for each independent variable (subscales from CAARS) and dependent variable (SDS scores). Mediation models estimate the indirect effects of an independent variable (in this case, ADHD symptom severity) on a dependent variable (functional impairment) after accounting for a mediator (anxiety). We used 5,000 bootstrap resamples to provide stable estimates of direct, indirect, and total effects. Confidence intervals were established using the bias-corrected and ac-

Table 1. Demographic and clinical characteristic of adult ADHD group and healthy control

\begin{tabular}{|c|c|c|c|c|}
\hline Characteristic & $\operatorname{ADHD}(n=51)$ & Healthy control $(n=51)$ & $\mathrm{T}\left(\right.$ or $\left.\chi^{2}\right)$ & $p$ value \\
\hline Age $(y r)$ & $27.82 \pm 8.90$ & $24.33 \pm 4.86$ & 2.46 & 0.016 \\
\hline Gender, male & $33(64.7)$ & $33(64.7)$ & 0.00 & 0.582 \\
\hline \multicolumn{5}{|l|}{ Education } \\
\hline Elementary school & 2 & & 9.93 & 0.019 \\
\hline Middle school & 31 & 28 & & \\
\hline High school & 13 & 23 & & \\
\hline College & 5 & & & \\
\hline Marital status & & & 10.08 & $0.022 *$ \\
\hline Single (unmarried, divorced) & $40(78.4)$ & $44(86.3)$ & & \\
\hline Married & $11(21.6)$ & $7(13.7)$ & & \\
\hline \multicolumn{5}{|l|}{ Social economic status } \\
\hline Low & 3 & 2 & & \\
\hline Low to middle & 13 & 12 & & \\
\hline Middle & 32 & 17 & & \\
\hline Middle to high & 2 & 17 & & \\
\hline High & 0 & 3 & & \\
\hline CAARS-In & $22.27 \pm 6.99$ & $11.51 \pm 50.32$ & & $0.000^{*}$ \\
\hline CAARS-Hy & $18.67 \pm 7.66$ & $12.16 \pm 50.25$ & & $0.000 *$ \\
\hline CAARS-Im & $20.31 \pm 7.45$ & $10.51 \pm 60.24$ & & $0.000^{*}$ \\
\hline CAARS-SC & $12.20 \pm 4.57$ & $7.35 \pm 40.46$ & & $0.000^{*}$ \\
\hline $\mathrm{BDI}$ & $19.33 \pm 10.66$ & $8.57 \pm 70.33$ & & $0.000^{*}$ \\
\hline STAI-T & $55.71 \pm 12.95$ & $41.24 \pm 100.45$ & & $0.000^{*}$ \\
\hline SDS 1 & $5.36 \pm 3.45$ & $4.04 \pm 20.84$ & & $0.038^{*}$ \\
\hline SDS 2 & $5.61 \pm 3.23$ & $4.35 \pm 20.54$ & & $0.032 *$ \\
\hline SDS 3 & $5.76 \pm 3.15$ & $4.02 \pm 20.83$ & & $0.004 *$ \\
\hline SDS total & $16.73 \pm 8.66$ & $12.41 \pm 70.09$ & & $0.007^{*}$ \\
\hline
\end{tabular}

Values are presented as mean \pm standard deviation, number only or number (\%).

ADHD, attention deficit hyperactivity disorder; CAARS, Conners' Adult ADHD Rating Scale; CAARS-In, CAARS inattention/memory problems; CAARS-Hy, CAARS hyperactivity/restlessness; CAARS-Im, CAARS impulsivity/emotional lability; CAARS-Sc, CAARS problems with self-concept; BDI, Beck Depression Inventory; STAI-T, Spielberg Trait Anxiety Inventory; SDS, Sheehan Disability Scale; SDS 1, SDS work/school; SDS 2, SDS social life/leisure activities; SDS 3, SDS family life/home responsibilities.

${ }^{*} p<0.05$. 
celerated method. Mediation was tested using the Hayes $^{40)}$ PROCESS modeling approach in model 4 of IBM SPSS Statistics software version 21.0 (IBM Co., Armonk, NY, USA). This analytic approach permitted the examination of both direct and indirect effects of ADHD symptom severity and anxiety on functional impairment in subjects with adult ADHD.

All tests were two-tailed, and alpha level was set at 0.05 for all analyses. We calculated all statistics using IBM SPSS Statistics software version 21.0.

\section{RESULTS}

Demographic and clinical characteristics for the two groups are shown in Table 1. The study sample included 51 ADHD adults (33 males and 18 females) and 51 healthy control subjects ( 33 males and 18 females). There was no significant difference in gender distribution, which was statistically controlled. There were significant between group differences in age, education levels, and marital status. Subjects in the ADHD group showed significantly higher CAARS $(p<0.001)$, BDI $(p<0.001)$,
STAI-T $(p<0.001)$, and SDS ( $p=0.007)$ scores compared to healthy controls.

Pearson correlations between SDS and psychological symptoms including BDI, STAI-T, and CAARS were significant. Higher psychological symptom severity (i.e., depression, anxiety, and ADHD symptoms) was associated with worse functional impairment (Table 2).

We conducted a regression-based mediation analysis according to Preacher and Hayes ${ }^{41)}$ for all four measures of ADHD (i.e., inattention/executive function, hyperactivity/restlessness, impulsivity/emotional lability, and problems with self-concept). ADHD symptoms served as predictors, SDS scores served as the criterion, and STAI-T scores served as mediators in this analysis (Figs. 1-4). Whereas the indirect effects of inattention $(B=0.523$, standard error $[S E]=0.150,95 \%$ confidence interval $[\mathrm{Cl}]=$ $0.285-0.872)$, hyperactivity $(B=0.254, S E=0.090,95 \%$ $\mathrm{Cl}=0.107-0.458)$, impulsivity $(\mathrm{B}=0.338, \mathrm{SE}=0.123,95 \%$ $\mathrm{Cl}=0.114-0.608)$, and problems with self-concept $(B=1.06, S E=0.287,95 \% C l=0.561-1.691)$ via anxiety were significant, the direct effects of inattention, hyperactivity, impulsivity, and problems with self-concept were

Table 2. Correlations between SDS and psychological symptoms in patients with ADHD

\begin{tabular}{|c|c|c|c|c|c|c|}
\hline & 1 & 2 & 3 & 4 & 5 & 6 \\
\hline \multicolumn{7}{|l|}{ 1. SDS } \\
\hline 2. CAARS-In & $0.379 * *$ & & & & & \\
\hline 3. CAARS-Hy & $0.401^{* *}$ & $0.369^{* *}$ & & & & \\
\hline 4. CAARS-Im & $0.598^{* * *}$ & $0.578^{* * *}$ & $0.663^{* * *}$ & & & \\
\hline 5. CAARS-SC & $0.296^{*}$ & $0.577^{* * *}$ & 0.187 & $0.460 * *$ & & \\
\hline 6. BDI & $0.562^{* * *}$ & $0.430^{* *}$ & $0.379 * *$ & $0.588^{* * *}$ & $0.432^{* *}$ & \\
\hline 7. STAI-T & $0.669^{* * *}$ & $0.653^{* * *}$ & $0.428^{* *}$ & $0.664^{* * *}$ & $0.690^{* * *}$ & $0.754^{* * *}$ \\
\hline
\end{tabular}

SDS, Sheehan Disability Scale; ADHD, attention deficit hyperactivity disorder; CAARS, Conners' Adult ADHD Rating Scale; CAARS-In, CAARS inattention/memory problems; CAARS-Hy, CAARS hyperactivity/restlessness; CAARS-Im, CAARS impulsivity/emotional lability; CAARS-Sc, CAARS problems with self-concept; BDI, Beck Depression Inventory; STAI-T, Spielberg Trait Anxiety Inventory.

${ }^{*} p<0.05,{ }^{* *} p<0.01,{ }^{* * *} p<0.001$.

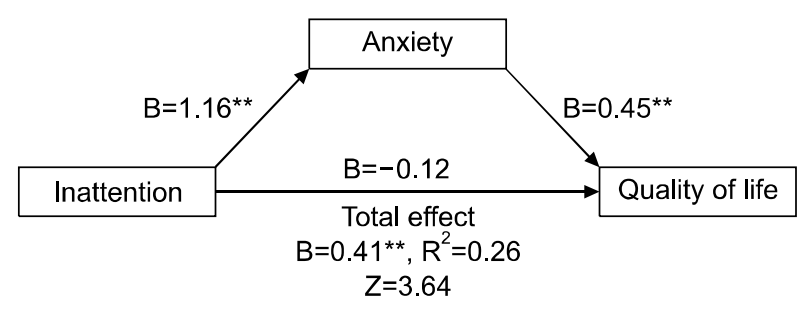

Fig. 1. Anxiety mediation models of the relationship between inattention and functional impairment. ${ }^{*} p<0.05,{ }^{* *} p<0.01$.

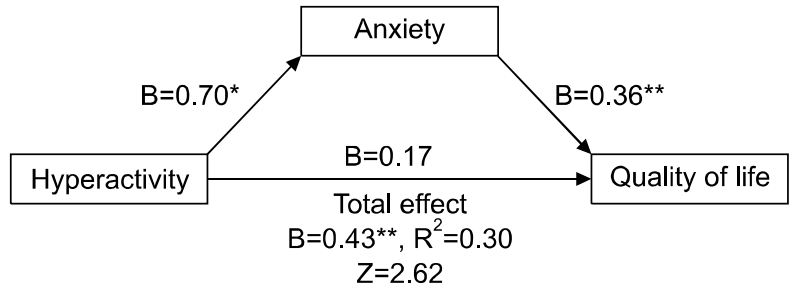

Fig. 2. Anxiety mediation models of the relationship between hyperactivity and functional impairment. ${ }^{*} p<0.05,{ }^{* *} p<0.01$. 


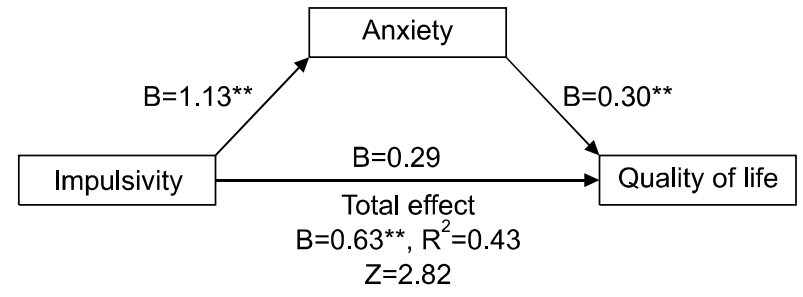

Fig. 3. Anxiety mediation models of the relationship between impulsivity and functional impairment. ${ }^{* *} p<0.01$

not significant. Given that the total effects were significant and the direct effects were not significant, we are able to conclude that the pathway between ADHD symptom severity and functional impairment is completely mediated by anxiety.

\section{DISCUSSION}

The primary goal of this study was to examine the associations between ADHD symptoms, anxiety, and functional impairment in adult patients with ADHD. Mediation analysis revealed significant indirect effects of inattention, hyperactivity, emotional lability/impulsivity, and problems with self-concept, but these were uniquely mediated by anxiety. This study represents the first investigation to empirically test the hypothesis that ADHD symptoms affect functional impairment via the influence of ADHD symptoms on anxiety among adult ADHD patients.

This study identified anxiety as a mediator between ADHD symptom severity and functional impairment. Anxiety has been investigated in various psychiatric disorders. Previous research has reported that anxiety is a significant relevant factor predicting treatment response and prognosis. High anxiety sensitivity is a key predictor for panic disorder severity. ${ }^{42)}$ In addition, according to recent research, anxiety sensitivity is a risk factor for mood disorder, psychosomatic disorder, post-traumatic stress disorder, and so on. ${ }^{43-45)}$ Some reports claim that suicide ideation is related to anxiety sensitivity, ${ }^{46)}$ and poor impulse control combined with high anxiety may impact suicidal ideation and suicide attempts. ${ }^{47)}$ Generally, ADHD patients suffer from impulsivity, response inhibition, and reward delay problems. ${ }^{48,49)}$ Anxiety comorbid with ADHD has been shown to predict poor behavioral regulation $^{50)}$ and enhanced the association between ADHD

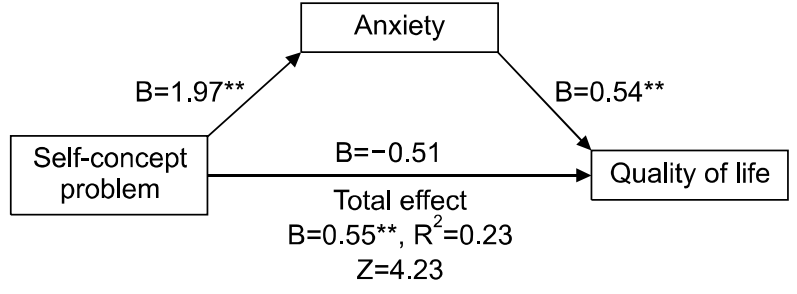

Fig. 4. Anxiety mediation models of the relationship between problems with self-concept and functional impairment. ** $p<0.01$.

and oppositional defiant disorder/conduct disorder. ${ }^{51)}$ Comorbid anxiety has been shown to be an important precursor, contributing to the development of externalizing problems in ADHD children. ${ }^{51-55)}$ A better understanding of factors that influence anxiety may be beneficial for targeting areas in need of improvement in the diagnosis and treatment of ADHD. Considering comorbid anxiety in adult ADHD treatment will contribute to improve treatment outcome and quality of life.

This study confirmed previous findings on the existence of functional impairment in adult ADHD patients. Although SDS scores among subjects in this study were under the cut-off value (remission $<6$ ), adult ADHD patients were shown to have significantly higher functional impairment than healthy control subjects. Additionally, we also revealed higher anxiety levels in adults with ADHD and a significant association between anxiety and ADHD symptom severity. These findings are consistent with the results of previous studies. ${ }^{56)}$ Recent studies have shown that both ADHD and anxiety disorders share a genetic pathophysiology. ${ }^{57,58)}$ The mechanisms involved in this association need to be further studied.

Our results indicated that all the subscales of ADHD mediated by trait anxiety had significant effects on functional impairment. Among all the subscales of CAARS, predominantly impulsivity/emotional lability mediated by trait anxiety. Emotional dysregulation is a major core ADHD symptom, and has been shown to predict adult ADHD severity independent of comorbid disorders. ${ }^{59)}$ Consistent with previous reports, impulsivity significantly affected functional impairment in ADHD adults. Persistent impulsive ADHD symptoms in adulthood indicate behavioral inhibition dysfunction due to delayed brain maturation, which could eventually be a major functional impairment source. ${ }^{60,61)}$ These results have important implications for ADHD treatment strategies and/or prognosis. 
While inattention, hyperactivity, and impulsivity cause functional impairment in ADHD adults, problems with self-concept also lead to functional impairment. Previous researches reported that patients with adult ADHD showed significantly greater self-concept problems compared to control groups. ${ }^{62-64)}$ Problems with self-concept included negative beliefs about the self-caused individuals to develop maladaptive coping strategies, including avoidance and procrastination. Also, untreated ADHD has been associated with decreased social skills, including poor peer or familial relationships, riskier sexual/physical activity, and increased peer victimization/ bullying. ${ }^{65,66)}$

This study has some limitations. First, for adult patients with ADHD, the study did not exclude comorbid disorders. We recruited adult patients with ADHD referred from a community sample, including some patients with comorbid disorders. Some selection bias may exist. However, ADHD is frequently comorbid with psychiatric illness in almost $80 \%$ of subjects. ${ }^{67,68)}$ Accordingly, this sample may reflect a community sample of adult ADHD patients. Second, we measured attentional problems and impulsivity using self-reports instead of objective assessments. Thus, individual discrepancies are likely to exist between objective symptom severity and self-reported symptom severity. Third, this study was cross-sectional, so causal relationships could not be established. Longitudinal prospective studies will be needed to confirm our results. Fourth, we did not assess possible comorbidities in healthy control subjects. In addition, psychiatric history was not excluded in the control group. It is possible that the STAI-T increments were due to potential factors not assessed in the current study, such as temperament, parenting style, or early life experiences. Nevertheless, this study utilized structured and systematic interview-based instruments to evaluate aspects of adult ADHD that are relatively difficult to detect. We improved statistical power by controlling for age, sex-based factors in the analysis.

In conclusion, this study provided strong evidence that anxiety management must be treated as an important aspect of comprehensive therapeutic strategies for adult ADHD patients. Generally, psychiatrists and physicians recognize adult $\mathrm{ADHD}$ as a prognosis of benign-spontaneous remission, so less clinical attention is paid to adult ADHD compared to child and adolescent ADHD. This study intended to encourage more clinical attention to and consideration of ADHD diagnosis in adult patients with psychiatric illness.

\section{REFERENCES}

1. Swanson JM, Sergeant JA, Taylor E, Sonuga-Barke EJ, Jensen PS, Cantwell DP. Attention-deficit hyperactivity disorder and hyperkinetic disorder. Lancet 1998;351:429-433.

2. Biederman J, Mick E, Faraone SV. Age-dependent decline of symptoms of attention deficit hyperactivity disorder: impact of remission definition and symptom type. Am J Psychiatry 2000;157:816-818.

3. Faraone SV, Biederman J, Mick E. The age-dependent decline of attention deficit hyperactivity disorder: a meta-analysis of follow-up studies. Psychol Med 2006;36:159-165.

4. Faraone SV, Biederman J. What is the prevalence of adult ADHD? Results of a population screen of 966 adults. J Atten Disord 2005;9:384-391.

5. Kessler RC, Adler L, Barkley R, Biederman J, Conners CK, Demler $\mathrm{O}$, et al. The prevalence and correlates of adult $A D H D$ in the United States: results from the National Comorbidity Survey Replication. Am J Psychiatry 2006;163: 716-723.

6. Barkley RA, Fischer M, Smallish L, Fletcher K. The persistence of attention-deficit/hyperactivity disorder into young adulthood as a function of reporting source and definition of disorder. J Abnorm Psychol 2002;111:279-289.

7. Murphy K, Barkley RA. Attention deficit hyperactivity disorder adults: comorbidities and adaptive impairments. Compr Psychiatry 1996;37:393-401.

8. Barkley RA, Fischer M, Smallish L, Fletcher K. Young adult follow-up of hyperactive children: antisocial activities and drug use. J Child Psychol Psychiatry 2004;45:195-211.

9. Biederman J, Petty CR, Monuteaux MC, Fried R, Byrne D, Mirto T, et al. Adult psychiatric outcomes of girls with attention deficit hyperactivity disorder: 11-year follow-up in a longitudinal case-control study. Am J Psychiatry 2010;167: 409-417.

10. Biederman J, Monuteaux MC, Mick E, Spencer T, Wilens TE, Silva JM, et al. Young adult outcome of attention deficit hyperactivity disorder: a controlled 10-year follow-up study. Psychol Med 2006;36:167-179.

11. Chorozoglou M, Smith E, Koerting J, Thompson MJ, Sayal K, Sonuga-Barke EJ. Preschool hyperactivity is associated with long-term economic burden: evidence from a longitudinal health economic analysis of costs incurred across childhood, adolescence and young adulthood. J Child Psychol Psychiatry 2015;56:966-975.

12. Jung $\mathrm{C}$, Choi S, Jeong S, Song C, Seo W, Chung US, et al. Multicenter, open-label study to evaluate the effects of methylphenidate-OROS (Concerta?) on cognitive functions in children with attention deficit hyperactivity disorder. Clin Psychopharmacol Neurosci 2007;5:31-37.

13. Asherson P, Akehurst R, Kooij JJ, Huss M, Beusterien K, Sasané 
$\mathrm{R}$, et al. Under diagnosis of adult ADHD: cultural influences and societal burden. I Atten Disord 2012;16(5 Suppl): 20S-38S.

14. Fayyad J, De Graaf R, Kessler R, Alonso J, Angermeyer M, Demyttenaere $\mathrm{K}$, et al. Cross-national prevalence and correlates of adult attention-deficit hyperactivity disorder. $\mathrm{Br} J$ Psychiatry 2007; 190:402-409.

15. Newcorn JH, Weiss M, Stein MA. The complexity of $A D H D$ : diagnosis and treatment of the adult patient with comorbidities. CNS Spectr 2007;12(8 Supp/ 12):1-14; quiz 15-6.

16. Nutt DJ, Fone K, Asherson P, Bramble D, Hill P, Matthews K, et al. Evidence-based guidelines for management of attention-deficit/hyperactivity disorder in adolescents in transition to adult services and in adults: recommendations from the British Association for Psychopharmacology. J Psychopharmacol 2007;21:10-41.

17. Brod M, Schmitt E, Goodwin M, Hodgkins P, Niebler G. $A D H D$ burden of illness in older adults: a life course perspective. Qual Life Res 2012;21:795-799.

18. Lensing MB, Zeiner P, Sandvik L, Opjordsmoen S. Quality of life in adults aged 50+ with ADHD. I Atten Disord 2015; 19:405-413.

19. Gjervan $\mathrm{B}$, Torgersen $\mathrm{T}$, Rasmussen $\mathrm{K}$, Nordahl HM. $A D H D$ symptoms are differentially related to specific aspects of quality of life. J Atten Disord 2014; 18:598-606.

20. Sobanski E, Brüggemann D, Alm B, Kern S, Deschner M, Schubert T, et al. Psychiatric comorbidity and functional impairment in a clinically referred sample of adults with attention-deficithyperactivity disorder (ADHD). Eur Arch Psychiatry Clin Neurosci 2007;257:371-377.

21. Uchida M, Spencer TJ, Faraone SV, Biederman J. Adult outcome of $A D H D$ : An overview of results from the MGH longitudinal family studies of pediatrically and psychiatrically referred youth with and without ADHD of both sexes. J Atten Disord 2015. doi: 10.1177/1087054715604360. [Epub ahead of print]

22. Gaynes BN, Magruder KM, Burns BJ, Wagner HR, Yarnall KS, Broadhead WE. Does a coexisting anxiety disorder predict persistence of depressive illness in primary care patients with major depression? Gen Hosp Psychiatry 1999;21:158-167.

23. Hensley L, Varela RE. PTSD symptoms and somatic complaints following Hurricane Katrina: the roles of trait anxiety and anxiety sensitivity. J Clin Child Adolesc Psychol 2008; 37:542-552.

24. March JS, Swanson JM, Arnold LE, Hoza B, Conners CK, Hinshaw SP, et al. Anxiety as a predictor and outcome variable in the multimodal treatment study of children with $A D H D$ (MTA). J Abnorm Child Psychol 2000;28:527-541.

25. Schmidt NB, Buckner JD, Keough ME. Anxiety sensitivity as a prospective predictor of alcohol use disorders. Behav Modif 2007;31:202-219.

26. Nima AA, Rosenberg P, Archer T, Garcia D. Anxiety, affect, self-esteem, and stress: mediation and moderation effects on depression. PLoS One 2013;8:e73265.

27. Ginsburg GS, La Greca AM, Silverman WK. Social anxiety in children with anxiety disorders: relation with social and emotional functioning. J Abnorm Child Psychol 1998;26:175185.

28. Richardson M, Abraham C, Bond R. Psychological correlates of university students' academic performance: a systematic review and meta-analysis. Psychol Bull 2012;138:353-387.

29. Kroenke K, Outcalt S, Krebs E, Bair MJ, Wu J, Chumbler N, et al. Association between anxiety, health-related quality of life and functional impairment in primary care patients with chronic pain. Gen Hosp Psychiatry 2013;35:359-365.

30. Sheehan DV, Lecrubier Y, Sheehan KH, Amorim P, Janavs J, Weiller E, et al. The Mini-International Neuropsychiatric Interview (M.I.N.I.): the development and validation of a structured diagnostic psychiatric interview for DSM-IV and ICD-10. J Clin Psychiatry 1998;59 Suppl 20:22-33; quiz 34-57.

31. Conners CK, Erhardt D, Sparrow EP. Conners' adult ADHD rating scales (CAARS): technical manual. North Tonawanda, NY:Multi-Health Systems Inc.;1999.

32. Beck AT, Steer RA, Carbin MG. Psychometric properties of the Beck Depression Inventory: Twenty-five years of evaluation. Clin Psychol Rev 1988;8:77-100.

33. Spielberger CD. State-trait anxiety inventory. In: Weiner IB, Craighead WE, editors. The Corsini encyclopedia of psychology. 4th ed. Hoboken:John Wiley \& Sons, Inc.;2010.

34. Leon AC, Olfson M, Portera L, Farber L, Sheehan DV. Assessing psychiatric impairment in primary care with the Sheehan Disability Scale. Int I Psychiatry Med 1997;27: 93-105.

35. Kim H, Lee J, Cho S, Lee IS, Kim JH. A preliminary study on reliability and validity of the Conners adult ADHD rating scalesKorean version in college students. Korean J Clin Psychol 2005;24:171-185.

36. Sung HM, Kim JB, Park YN, Bai DS, Lee SH, Ahn HN. A study on the reliability and the validity of Korean version of the Beck Depression Inventory-II (BDI-II). J Korean Soc Bio Ther Psychiatry 2008;14:201-212.

37. Hahn DW, Lee CH, Chon KK. Korean adaptation of Spielberger's STAI (K-STAI). Korean J Health Psychol 1996; 1:1-14.

38. Sheehan DV, Harnett-Sheehan K, Raj BA. The measurement of disability. Int Clin Psychopharmacol 1996;11 Suppl 3: 89-95.

39. Park J, Kim J. Korean version of the Sheehan disability scale (SDS): reilability and validity. Korean I Clin Psychol 2010; 29:73-81.

40. Hayes AF. Introduction to mediation, moderation, and conditional process analysis: a regression-based approach. New York:Guilford Press;2013.

41. Preacher KJ, Hayes AF. Asymptotic and resampling strategies for assessing and comparing indirect effects in multiple medi- 
ator models. Behav Res Methods 2008;40:879-891.

42. Kang EH, Kim B, Choe AY, Lee JY, Choi TK, Lee SH. Panic disorder and health-related quality of life: the predictive roles of anxiety sensitivity and trait anxiety. Psychiatry Res 2015;225: 157-163.

43. Kiliç EZ, Kiliç C, Yilmaz S. Is anxiety sensitivity a predictor of PTSD in children and adolescents? I Psychosom Res 2008; 65:81-86.

44. Watt MC, Stewart SH. Anxiety sensitivity mediates the relationships between childhood learning experiences and elevated hypochondriacal concerns in young adulthood. J Psychosom Res 2000:49:107-118.

45. Weems CF, Hammond-Laurence K, Silverman WK, Ferguson C. The relation between anxiety sensitivity and depression in children and adolescents referred for anxiety. Behav Res Ther 1997:35:961-966.

46. Capron DW, Fitch K, Medley A, Blagg C, Mallott M, Joiner T. Role of anxiety sensitivity subfactors in suicidal ideation and suicide attempt history. Depress Anxiety 2012;29:195-201.

47. Apter A, Plutchik R, van Praag HM. Anxiety, impulsivity and depressed mood in relation to suicidal and violent behavior. Acta Psychiatr Scand 1993;87:1-5.

48. Groman SM, James AS, Jentsch JD. Poor response inhibition: at the nexus between substance abuse and attention deficithyperactivity disorder. Neurosci Biobehav Rev 2009;33: 690-698.

49. Wilbertz G, van Elst LT, Delgado MR, Maier S, Feige B, Philipsen A, et al. Orbitofrontal reward sensitivity and impulsivity in adult attention deficit hyperactivity disorder. Neuroimage 2012;60:353-361.

50. Sørensen L, Plessen KJ, Nicholas J, Lundervold AJ. Is behavioral regulation in children with ADHD aggravated by comorbid anxiety disorder? J Atten Disord 2011;15:56-66.

51. Humphreys KL, Aguirre VP, Lee SS. Association of anxiety and $O D D / C D$ in children with and without $A D H D$. J Clin Child Adolesc Psychol 2012;41:370-377.

52. Bubier JL, Drabick DA. Co-occurring anxiety and disruptive behavior disorders: the roles of anxious symptoms, reactive aggression, and shared risk processes. Clin Psychol Rev 2009; 29:658-669.

53. Carré JM, Fisher PM, Manuck SB, Hariri AR. Interaction between trait anxiety and trait anger predict amygdala reactivity to angry facial expressions in men but not women. Soc Cogn Affect Neurosci 2012;7:213-221.

54. Gregory AM, Eley TC, Plomin R. Exploring the association between anxiety and conduct problems in a large sample of twins aged 2-4. J Abnorm Child Psychol 2004;32:111-122.

55. Marmorstein NR. Relationships between anxiety and externalizing disorders in youth: the influences of age and gender. J Anxiety Disord 2007;21:420-432.

56. Liu TL, Yang P, Ko CH, Yen JY, Yen CF. Association between $A D H D$ symptoms and anxiety symptoms in Taiwanese adolescents. J Atten Disord 2014;18:447-455.

57. Faraone SV, Biederman J. Is attention deficit hyperactivity disorder familial? Harv Rev Psychiatry 1994;1:271-287.

58. Pliszka SR, Maas JW, Javors MA, Rogeness GA, Baker J. Urinary catecholamines in attention-deficit hyperactivity disorder with and without comorbid anxiety. I Am Acad Child Adolesc Psychiatry 1994;33:1165-1173.

59. Corbisiero S, Mörstedt B, Bitto H, Stieglitz RD. Emotional dysregulation in adults with attention-deficit/hyperactivity disorder-validity, predictability, severity, and comorbidity. J Clin Psychol 2017;73:99-112.

60. Giedd JN, Rapoport JL. Structural MRI of pediatric brain deve/opment: what have we learned and where are we going? Neuron 2010;67:728-734.

61. Yoo JH, Oh Y, Jang B, Song J, Kim J, Kim S, et al. The effects of equine-assisted activities and therapy on resting-state brain function in attention-deficit/hyperactivity disorder: a pilot study. Clin Psychopharmacol Neurosci 2016;14:357-364.

62. Michielsen M, Comijs HC, Semeijn EJ, Beekman AT, Deeg DJ, Kooij JJ. Attention deficit hyperactivity disorder and personality characteristics in older adults in the general Dutch population. Am J Geriatr Psychiatry 2014;22:1623-1632.

63. Michielsen M, de Kruif JT, Comijs HC, van Mierlo S, Semeijn EJ, Beekman AT, et al. The burden of ADHD in older adults: a qualitative study. J Atten Disord 2015. doi: 10.1177/ 1087054715610001. [Epub ahead of print]

64. Szuromi B, Bitter I, Czobor P. Functional impairment in adults positively screened for attention-deficit hyperactivity disorder: the role of symptom presentation and executive functioning. Compr Psychiatry 2013;54:974-981.

65. Hoza B. Peer functioning in children with ADHD. J Pediatr Psychol 2007;32:655-663.

66. Mrug S, Molina BS, Hoza B, Gerdes AC, Hinshaw SP, Hechtman $\mathrm{L}$, et al. Peer rejection and friendships in children with attention-deficit/hyperactivity disorder: contributions to long-term outcomes. J Abnorm Child Psychol 2012;40:10131026.

67. Shim SH, Kwon YJ. Adolescent with Tourette syndrome and bipolar disorder: a case report. Clin Psychopharmacol Neurosci 2014;12:235-239.

68. Biederman J, Wilens T, Mick E, Milberger S, Spencer TJ, Faraone SV. Psychoactive substance use disorders in adults with attention deficit hyperactivity disorder (ADHD): effects of $A D H D$ and psychiatric comorbidity. Am J Psychiatry 1995:152:1652-1658. 